\title{
Endoscopic versus Microscopic Transsphenoidal Hypophysectomy: Comparison of the Endocrine Outcome - An Institutional Experience
}

\author{
Robert Sumkovski $^{1 *}$, Ivica Kocevski ${ }^{1}$, Micun Micunovic ${ }^{2}$ \\ ${ }^{1}$ University Clinic of Neurosurgery, Faculty of Medicine, Ss Cyril and Methodius University of Skopje, Skopje, Republic of \\ Macedonia; 'Special Hospital for Orthopedic Surgery and Traumatology "St. Erazmo," Ohrid, Republic of Macedonia
}

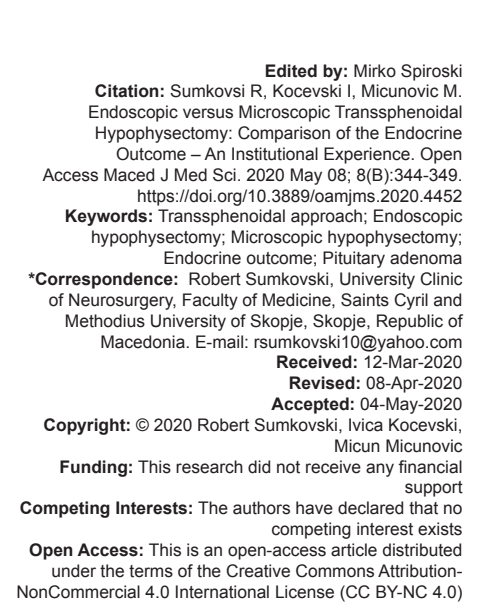

\section{Introduction}

Pituitary adenoma is the third most common intracranial tumor in surgical practice, accounting for approximately $10-25 \%$ of all intracranial tumors [1]. Recent epidemiological data suggest that clinically apparent pituitary adenomas have a prevalence of $1 / 1000$ in the general population [2], [3]. Although only very rarely malignant, pituitary tumors may cause significant morbidity in affected patients where why they demand total resection, and their treatment remains challenge [4].

Transsphenoidal surgery of the pituitary evolves continually beginning from the early $20^{\text {th }}$ century, initially assigned by Schmidt et al., which were the first to report a sellar tumor through transsphenoidal route in 1907 [5], [6]. Cushing successively focused and popularized sublabial transseptal transsphenoidal corridor in the following decades [7]. Abandoned for several decades, this technique revived with Hardy in the early 1960s, introducing the operative microscope nearly becomes a standard approach causes it provided minimal morbidity and mortality [8]. The rapid global expand in the past two-three decades emerged with Jankowski, who proposed fully endoscopic approach to pituitary lesions in 1992 [9]. The current high-tech development of optics, radiodiagnostics, high sensitivity radio essays, informatics, instrumentation, surgical devices, and utility tissue high-tech materials incorporated with human innate sickness for prospect, lead to milestone progress at this field. Endoscopic transsphenoidal surgery presents safe, efficacious, effective, and minimally invasive surgery of the pituitary, which allows surgeons to gain access to central skull base lesions in a secure manner defining probably the gold standard for the future.

Comprehensive cadaveric dissections, with $3 \mathrm{D}$ evaluation in the learning curve of the pituitary 
surgeons, provided meaningful baseline for expansion in this field [10].

The current endoscopes are two dimensional and cannot provide stereoscopic three-dimensional view compared with the operative microscope. This fact dictates evaluated equivocal rationale and balanced dialectics between these two technologies. The emerging new technology of 3D multilocular polifilament endoscopes supposed to overwhelm this insufficiency.

The purpose of this study was to compare the outcomes and the complications associated with these techniques by comparing endoscopic with microscopic surgery in the treatment of pituitary adenomas, emphasizing the endocrine aspect.

\section{Materials and Methods}

Our study included eighty-five patients harboring pituitary adenoma, operated in our institution during the period of 2011-2018. According to the technology, they were separated in two groups. The first group of 46 patients treated with transsphenoidal microscopic and endoscopically assisted microscopic technique and the second group of 39 patients operated on fully endoscopically.

\section{Inclusion criteria}

The following criteria were included in the study:

- $\quad$ Patients with adenoma over 14 years old

- $\quad$ Patients with clinically evident adenoma

- $\quad$ Patients with sellar lesion, according to the configuration, volume, and anatomy provide safe transsphenoidal endoscopic resection without distortion

- $\quad$ Intact diaphragm
Patients with supra and parasellar lesion, previously assessed for two steps resection, initially transnasal

- $\quad$ Patients with microadenoma with Cushing disease

Previously transsphenoidal microscopically operated patients with recurrens and clinical manifestation

\section{Exclusion criteria}

The following criteria were excluded from the study:

- $\quad$ Patients bellow 14 years old

- Lesions unfavorable anatomically for safe endoscopic resection (kissing carotids, high suprasellar and/or parasellar, intraorbital propagation, or cavernous sinus engagement) Other histopathological lesions

- Microadenomas favorable for conservative treatment

Previously endoscopically treated patients with evident complication and high risk

Comprehensive neurological examination including motor, sensory, and cranial nerve examination has been performed, including visual field, acuity, fundus, and evoked potentials. Routine blood and basic hormonal profile were performed. Magnetic resonance imaging (MRI) brain and paranasal sinuses including sella computed tomography (CT) were performed in all patients. All patients underwent the standardized microscopic or endoscopic procedure and were provided a uniform post-operative care.

All procedures were performed under general anesthesia with orotracheal intubation.

We used $4 \mathrm{~mm}$ diameter sinonasal rigid endoscope, "Karl Storz," Tuttlingen, Germany, spheric $0-0$ and $30^{\circ}$. Initial phase was decongestive of the mucosa of the septum and turbinates. Consecutively, the middle meatus and sphenoid rostrum have been identified and drilled to enter the sphenoid. Delicate drilling was to open the sellar floor. The dura was opened in a crucial manner. Further, with delicate dissection with the pituitary instruments, the tumor has been removed, primarily posterior and superior aspect and finally lateral and anterior portion prospectively. Second, the tumor site, the sella has been inspected with a $30^{\circ}$ endoscope. After the tumor resection, the basal cisternal arachnoid emerges downward pulsating. Hemostasis is completed usually with Surgiflo liquid surgical. The tumor cavity and sphenoid were packed with fat and sealed with fibrin glue. Nasal packing was done with Merocel up to the middle meatus. In most cases, lumbar drain has been placed for $72 \mathrm{~h}$.

Microscopic surgery was standardized and similar, except introducing Hardy's nasal speculum and done under visualization with a microscope pp "Pentero," Zeiss, Germany.

The hormonal profile, highly sensitive assays, and visual function evaluation including VEP, MRI, and CT scanning were repeated immediately and after 1 month of surgery and were compared with preoperative findings, both for endoscopic and microscopic procedures.

\section{Statistical analysis}

Statistical analysis was performed with Statistica 7.1 for Windows and SPSS Statistics 23.0 (SPSS Inc., Chicago, IL, USA).

The analysis of the patient series with attributes (gender, clinical diagnosis, pre-operative hormone activity, type of pre-operative hormone activities, quantity of resection of the lesion, post-operative assay 
in secretory tumors, and the categorical data) were presented as numbers (percentage - \%).

The differences between the two technologies (microscopic transsphenoidal and endoscopic transsphenoidal surgery) were compared using Pearson Chi-square test ( $p)$, Pearson's Chi-square test/Monte Carlo sig. (p), and Fisher's exact test/Monte Carlo sig. (p).

The cross-tabulation between the two groups has been performed with Pearson's Chi-square test/ Monte Carlo sig. (p), and Fisher's Exact Test/Monte Carlo Sig. (p).

\section{Results}

Within the group microscopically treated, 33 were male and 13 female patients. Nineteen were male and 20 were female in the group treated endoscopically.

The mean age of the patients with microscopic procedure was $54.22 \pm 12.64$ years (ranged 28-75 years).

The mean age of the patients endoscopically treated was $50.87 \pm 12.65$ years (ranged $12-72$ years).

The results of the pre-operative hormone activities in both groups of pituitary adenomas are exposed in Table 1.

Table 1: Pre-operative hormone activities in both groups of pituitary adenomas

\begin{tabular}{llll}
\hline Variable & \multicolumn{2}{l}{ Pre-operative hormone activity } & Total \\
\cline { 2 - 3 } & Non-secretory (non-active) & Secretory (active) & \\
\hline Procedure & & & \\
Microscopic & & 33 & 46 \\
$\quad$ Count & 13 & 71.7 & 100.0 \\
$\quad \%$ & 28.3 & & \\
Endoscopic & & 28 & 39 \\
$\quad$ Count & 11 & 71.8 & 100.0 \\
$\quad \%$ & 28.2 & & \\
Total & & 61 & 85 \\
$\quad$ Count & 24 & 71.8 & 100.0 \\
$\%$ & 28.2 & & \\
\hline
\end{tabular}

Within the group of 46 microscopically treated, $13(28.30 \%)$ were secretory non-active and $33(71.70 \%)$ were functional, secretory active.

Within the group of 39 endoscopically treated, $11(28.20 \%)$ were preoperatively inactive, non-secretory and $28(71.80 \%)$ were secreting active adenomas.

By Pearson's Chi-square $=0.00$ and $p<0.05$ $(p=0.99)$, no significant difference according to the secretory activity has been noted.

Compared results postoperatively, according to the radicality of resection associated with secretory active adenomas are revealed in Table 2.

In the group of 33 secretory active microscopically treated lesions, 5 (15.20\%) remained unchanged, $18(54.50 \%)$ experienced partial non-significant
Table 2: Postoperatively results, according to the radicality of resection associated with secretory active adenomas

\begin{tabular}{|c|c|c|c|}
\hline \multirow{2}{*}{ Variable } & \multicolumn{2}{|c|}{ Post-operative assay in hormone secretory adenomas } & \multirow{2}{*}{ Total } \\
\hline & Significant improvement & Normalized & \\
\hline \multicolumn{4}{|c|}{ Radicality of resection } \\
\hline \multicolumn{4}{|c|}{ Up to $90 \%$} \\
\hline Count & 7 & 3 & 10 \\
\hline$\%$ & 70.0 & 30.0 & 100.0 \\
\hline \multicolumn{4}{|c|}{ Over $90 \%$} \\
\hline Count & 6 & 12 & 18 \\
\hline$\%$ & 33.3 & 66.7 & 100.0 \\
\hline \multicolumn{4}{|l|}{ Total } \\
\hline Count & 13 & 15 & 28 \\
\hline$\%$ & 46.4 & 53.6 & 100.0 \\
\hline
\end{tabular}

improvement, $9(27.30 \%)$ experienced significant improvement, and 1 (3.00\%), the vision was normalized.

In the group of 28 secretory active endoscopically treated lesions, 13 (46.40\%) postoperative vision has been significantly improved and 15 $(53.60 \%)$ had normalization of the vision.

For Fisher's exact test $=40.22$ and $p<0.001$ $(p=0.000) /$ Monte Carlo sig./0.000-0.000/there is a significant difference in post-operative assay between the groups of hormone active lesions treated microscopically and endoscopically.

The results of the post-operative assay of the group with endocrine active lesion microscopically treated, associated with the quantity degree of resection are evident in Table 3.

In the group of 33 patients with hormonally active microscopically treated lesion, in 7 (21.21\%), the resection has been achieved up to $50 \%$, in $22(66.67 \%)$ up to $75 \%$, and in $4(12.12 \%)$ subtotal resection up to $90 \%$.

Postoperatively, within the group of 7 patients with resection up to $50 \%$, in $4(57.10 \%)$, the hormone activity remained unchanged, and in 3 (42.90\%), the hormone activity improved partially.

In the same group, where the resection has been performed up to $75 \%$, in $1(4.50 \%)$ hormone activity remained unchanged, in 13 (59.10\%) partially improved, in 7 (31.80\%) significantly improved, and in 1 $(4.50 \%)$, the hormone activities have been normalized.

In four patients of this group, where the resection has been achieved up to $90 \%$, in $2(50.00 \%)$, the hormone activity has been partially improved and in $2(50.00 \%)$ significantly improved.

The cross-tabulation of the results between the degree quantity of resection and post-operative hormone activity for the lesions treated with transsphenoidal microscopic surgery for Fisher's exact test $=11.43$ and $p<0.05$ ( $p=0.033) /$ Monte Carlo sig./0.028-0.037/ delineated significant difference.

The group of 28 patients with pre-operative secretory active adenomas, treated with transsphenoidal endoscopic resection, comprised 10 (35.71\%) with subtotal resection up to $90 \%$ and 18 (64.29\%) with resection over $90 \%$.

Postoperatively, of the subgroup with subtotal resection up to $90 \%$, in $7(70.00 \%)$, the hormone 
Table 3: Post-operative assay of the group with endocrine active lesion microscopically treated, associated with the quantity degree of resection

\begin{tabular}{|c|c|c|c|c|c|}
\hline \multirow[t]{2}{*}{ Variable } & \multicolumn{4}{|c|}{ Post-operative assay in secretory active adenomas } & \multirow[t]{2}{*}{ Total } \\
\hline & Unchanged & Partially improved & Significantly improved & Normalized & \\
\hline \multicolumn{6}{|c|}{ Type of hormone activity preoperatively } \\
\hline \multicolumn{6}{|c|}{ STH secretory } \\
\hline Count & 0 & 7 & 1 & 0 & 8 \\
\hline$\%$ & 0.0 & 87.5 & 12.5 & 0.0 & 100.0 \\
\hline \multicolumn{6}{|c|}{ PLC secretory } \\
\hline Count & 3 & 1 & 0 & 0 & 4 \\
\hline$\%$ & 75.0 & 25.0 & 0.0 & 0.0 & 100.0 \\
\hline \multicolumn{6}{|c|}{ ACTH secretory } \\
\hline Count & 0 & 1 & 0 & 0 & 1 \\
\hline$\%$ & 0.0 & 100.0 & 0.0 & 0.0 & 100.0 \\
\hline \multicolumn{6}{|c|}{ TSH secretory } \\
\hline Count & 0 & 0 & 1 & 0 & 1 \\
\hline$\%$ & 0.0 & 0.0 & 100.0 & 0.0 & 100.0 \\
\hline \multicolumn{6}{|c|}{ STH, PLC secretory } \\
\hline Count & 2 & 9 & 7 & 1 & 19 \\
\hline$\%$ & 10.5 & 47.4 & 36.8 & 5.3 & 100.0 \\
\hline \multicolumn{6}{|l|}{ Total } \\
\hline Count & 5 & 18 & 9 & 1 & 33 \\
\hline$\%$ & 15.2 & 54.5 & 27.3 & 3.0 & 100.0 \\
\hline
\end{tabular}

activity was significantly improved and in $3(30.00 \%)$ normalized.

The compared results of post-operative hormone assay of the two groups of patients treated microscopically and endoscopically are exposed in Table 4.

Table 4: Results of post-operative hormone assay of the two groups of patients treated microscopically and endoscopically

\begin{tabular}{|c|c|c|c|c|c|}
\hline \multirow{2}{*}{ Variable } & \multicolumn{4}{|c|}{ Post-operative assay in secretory active adenomas } & \multirow[t]{2}{*}{ Total } \\
\hline & Unchanged & $\begin{array}{l}\text { Partially } \\
\text { improved }\end{array}$ & $\begin{array}{l}\text { Significantly } \\
\text { improved }\end{array}$ & Normalized & \\
\hline \multicolumn{6}{|l|}{ Procedure } \\
\hline \multicolumn{6}{|c|}{ Microscopic } \\
\hline Count & 5 & 18 & 9 & 1 & 33 \\
\hline$\%$ & 15.2 & 54.5 & 27.3 & 3.0 & 100.0 \\
\hline \multicolumn{6}{|c|}{ Endoscopic } \\
\hline Count & 0 & 0 & 13 & 15 & 28 \\
\hline$\%$ & 0.0 & 0.0 & 46.4 & 53.6 & 100.0 \\
\hline \multicolumn{6}{|l|}{ Total } \\
\hline Count & 5 & 18 & 22 & 16 & 61 \\
\hline$\%$ & 8.2 & 29.5 & 36.1 & 26.2 & 100.0 \\
\hline
\end{tabular}

In 33 patients microscopically treated, $5(15.20 \%)$ remained unchanged, $18(54.50 \%)$ experienced partial improvement, 9 (27.30\%) experienced significant improvement, and in $1(3.00 \%)$, post-operative secretory activity was normalized.

In 28 patients endoscopically treated, 13 (46.40\%) experienced significant improvement, and in $15(53.60 \%)$, the post-operative hormone activity was normalized.

The Fisher's exact test $=40.22$ and $p<0.001$ $(p=0.000) /$ Monte Carlo Sig./0.000-0.000 depicted significant difference in the outcome pp post-operative hormone assay in the compared groups treated microscopically and endoscopically.

\section{Discussion}

Pituitary tumors surgery still represent a significant challenge, despite the highly refined nature, evolved high technology, informatics, and training and learning advance of the contemporary micro and endoscopic surgery. The endoscope as a device introduced to this technology has been widely accepted for the past three decades. High technology evolution of the optics provides progressive trends toward less invasive approach. Evidently, the endonasal endoscopic approach is less invasive, efficacious, safe, and effective to the pituitary gland and local surrounding structures, supplemented with better intraoperative illumination, image, angle, and wideness of surgical and working field.

Guiot is the recognized first pioneering surgeon introducing endoscope in transsphenoidal approach [11].

Reisch et al. defined that the endoscope contributes to comprehensive panorama to the anatomy, introducing the concept of minimally invasive surgery [12]. Song et al., in 1992, introduced the fully endoscopic concept as an approach to sellar region [13].

Keyworth et al. with largest prospective study series (215 patients) and Khan et al., with series of 170 patients traced the pathway of this technology as dominant and safe [14], [15].

First comparison between microscopic and endoscopic technique performed by Khan et al., in a retrospective study in 1999 [2], [15].

Yadav et al., presented comparison of the two technologies with evident improvement and advance of the transsphenoidal endoscopic versus transsphenoidal microscopic technology, concerning visuality, quantity of resection, and complication control [16].

Schwartz et al. proceeded step forward, defining the concept of balanced dialectics of both technologies.

Endoscopic transsphenoidal pituitary surgery is developing technique becoming nearly standard procedure for pituitary lesions, and consequent comparison with microscopic transsphenoidal surgery is and will be committed only to delineate the advantages and disadvantages. 
Three-dimensional visuality and almost unnecessary additional training for microneurosurgeons are still the advance.

On the other hand, endoscope provides full exquisite panorama of the surgical site, minimal damage to the nasal cavity, no invisible angle, better illumination, better vision and distinguisability of the lesion surface, better bleeding control, better bimanual manipulation, no speculum, in addition much wider surgical operating field better resection, less complication, less operative time, and early discharge.

Certainly, learning curve and process of training much more demand for this technology.

Furtheron, introducing the multifocal multifilament endoscope as a technological innovation provides 3D vision of the surgical field, eliminating the handicap compared to $3 \mathrm{D}$ operative microscope.

In our study, we present a comparison of these two technologies, the ability and quantity of resection, associated with endocrine function outcome compared pre- and postoperatively.

In the present study, there was safer and significantly more radical resection accomplished within the group endoscopically treated, consequently with better endocrine outcome and less complication.

This result is entirely compatible with the recent studies, $\mathrm{pp}$ previous prospective study done by Jain et al. who concluded less post-operative complication, less operative time in endoscopic transsphenoidal group as compared to transsphenoidal microscopic technology.

\section{Conclusion}

For the past decades, the endoscopic transsphenoidal pituitary surgery becomes a milestone in operative treatment of pituitary lesions mostly comprising adenomas. It provides direct endonasal minimally invasive corridor, panoramic view inside the sphenoid cavity, and sella. Endoscopic transsphenoidal pituitary adenoma surgery is defined as safe, efficacious, effective, minimally invasive, with wider and direct anatomical control of the operative field, better illumination, wide angle without blind angle field, resulting with greater, faster and safer potential of tumor excision with respect to the sphenoid, and sellar and parasellar anatomical structures. Conclusively, higher possibility and potential for more radical resection provided better general outcome result and free of disease interval including much better in our study, endocrine overall outcome.

\section{References}

1. Jane JA Jr., Catalino MP, Laws ER Jr. In: Feingold KR, Anawalt B, Boyce A, Chrousos G, editors. Surgical Treatment of Pituitary Adenomas.. In: Endotext South Dartmouth, MA: MDText.com, Inc.; 2000.

2. Prajapati HP, Jain SK, Sinha VD. Endoscopic versus microscopic pituitary adenoma surgery: An institutional experience. Asian J Neurosurg. 2018;13(2):217-21. https://doi.org/10.4103/ajns. ajns_160_16

PMid:29682011

3. Kopczak A, Renner U, Karl Stalla G. Advances in understanding pituitary tumors. F1000Prime Rep. 2014;6:5. https://doi. org/10.12703/p6-5

PMid:24592317

4. Lin AL, Sum MW, DeAngelis LM. Is there a role for early chemotherapy in the management of pituitary adenomas? Neuro Oncol. 2016;18(10):1350-6. https://doi.org/10.1093/ neuonc/now059

PMid:27106409

5. Liu JK, Das K, Weiss MH, Laws ER Jr, Couldwell WT. The history and evolution of transsphenoidal surgery. J Neurosurg. 2001;95(6):1083-96

PMid:11765830

6. Schmidt RF, Choudhry OJ, Takkellapati R, Eloy JA, Couldwell WT, Liu JK. Hermann Schloffer and the origin of transsphenoidal pituitary surgery. Neurosurg Focus. 2012;33(2):E5. https://doi. org/10.3171/2012.5.focus 12129

PMid:22853836

7. Cohen-Gadol AA, Liu JK, Laws ER Jr. Cushing's first case of transsphenoidal surgery: The launch of the pituitary surgery era. J Neurosurg. 2005;103(3):570-4. https://doi.org/10.3171/ jns.2005.103.3.0570

PMid:16235694

8. Shou XF, Li SQ, Wang YF, Zhao Y, Jia PF, Zhou LF. Treatment of pituitary adenomas with a transsphenoidal approach. Neurosurgery. 2005;56(2):249-56. https://doi.org/10.1227/01. neu.0000147976.06937.1d

PMid:15670373

9. Theodros D, Patel M, Ruzevick J, Lim M, Bettegowda C. Pituitary adenomas: Historical perspective, surgical management and future directions. CNS Oncol 2015;4(6):411-29. https://doi. org/10.2217/cns.15.21

PMid:26497533

10. Narayanan $V$, Narayanan $P$, Rajagopalan $R$, Karuppiah $R$, Rahman ZA, Wormald PJ, et al. Endoscopic skull base training using $3 \mathrm{D}$ printed models with pre-existing pathology. Eur Arch Otorhinolaryngol. 2015;272(3):753-7. https://doi.org/10.1007/ s00405-014-3300-3

PMid:25294050

11. Patel SK, Husain Q, Eloy JA, Couldwell WT, Liu JK. Norman Dott, Gerard Guiot, and Jules Hardy: Key players in the resurrection and preservation of transsphenoidal surgery. Neurosurg Focus 2012;33(2):E6. https://doi.org/10.3171/2012.6.focus12125 PMid:22853837

12. Reisch R, Stadie A, Kockro RA, Hopf N. The keyhole concept in neurosurgery. World Neurosurg. 2013;79(2 Suppl):S17.e9-13. https://doi.org/10.1016/j.wneu.2012.02.024 PMid:22381839

13. Song $\mathrm{Y}$, Li H, Liu H, Li W, Zhang X, Guo L, et al. Endoscopic endonasal transsphenoidal approach for sellar tumors beyond the sellar turcica. Acta Otolaryngol. 2014;134(3):326-30. https:// doi.org/10.3109/00016489.2013.857785 
PMid:24256041

14. Keyworth C, Hart J, Armitage CJ, Tully MP. What maximizes the effectiveness and implementation of technology-based interventions to support healthcare professional practice? A systematic literature review. BMC Med Inform Decis Mak. 2018;18(1):93. https://doi.org/10.1186/s12911-018-0661-3 PMid:30404638

15. Khan I, Shamim MS. Comparison between endoscopic and microscopic approaches for surgery of pituitary tumours. J Pak Med Assoc. 2017;67(11):1777-9.

PMid:29171583

16. Yadav $Y R$, Nishtha $Y$, Vijay $P$, Shailendra $R$, Yatin $K$ Endoscopic endonasal trans-sphenoid management of craniopharyngiomas. Asian J Neurosurg. 2015;10(1):10-6. https://doi.org/10.4103/1793-5482.151502

PMid:25767569 